\title{
Knowledge of Radiology Technicians Regarding Radiation Health Hazards and Radiation Safety Measures in Ain-Shams University Hospitals
}

\author{
${ }^{1}$ Ahmed EsmatShoman, ${ }^{1}$ Sally Adel Hakim, ${ }^{1}$ Mohamed Abdel MagidTolba, ${ }^{1}$ Dena \\ Ali Abozaid \\ ${ }^{1}$ Department Of Community, Environmental and Occupational Medicine, Faculty of \\ Medicine, Ain-Shams University \\ Received: March2016Accepted: June 2016
}

\begin{abstract}
Background: Radiation exposure in hospitals accounts for the largest number of workers occupationally exposed to radiation, hence radiation safety practice in medicine is mandatory. Objective:The study aim was to measure the knowledge of radiology technicians regarding radiation health hazards and radiation safety in Ain-Shams university hospitals in Egypt. Methodology:61 radiology technicians participated in the study, technicians were recruited from Ain-Shams university hospitals.Results:Technicians' radiation knowledge score was $10.53 \pm 3.8$. No association was found between technicians' age, gender, duration of experience in radiology, attending radiation safety courses or workplace and the radiation knowledge score. Conclusion and Recommendations: It is recommended to provide radiation safety courses.
\end{abstract}

Keywords: Radiation safety, knowledge, Radiation health hazards

Corresponding Author: Dena A. AbozaidEmail: drdenaali@outlook.com

\section{Introduction}

Radioactivity is theproperty to spontaneously give off energy as particles or rays ${ }^{1}$. Radiation is widely used in medicine for diagnostic and therapeutic purposes ${ }^{2}$.Medicine accounts for the largest number of workers occupationally exposed to ionizing radiation $^{3}$.

Awareness of ionizing radiation induced health hazards began early in 1902 when occurrence of skin cancer in radiologists raised questions about radiologists' safety and health hazards due to radiation exposure ${ }^{4}$. In 1940, it was noticed that there are increase in mortality rates due to leukemia among radiologists ${ }^{5,6,7}$. A study in 1958, to investigate mortality rates among British health care workers found that, there was an increase in deaths due to cancer among radiologists who practiced before1921 (as 1921 is the year when it was first advised to adopt radiation protection) ${ }^{8}$.

One of the fundamental reasons of excessive radiation exposure in medicine is the fact that many of the healthcare workers involved with radiation have received only basic radiation training and their knowledge about radiation safety measures may be insufficient.Previous studies showed that there was lack of radiation safety knowledge among radiation exposed workers in hospitals ${ }^{9}$.A study in Indonesia was conducted to assess radiology technicians' knowledge on radiation protection found that $69.3 \%$ of the technicians answered less than $50 \%$ of the questions correctly ${ }^{(\mathbf{1 0})}$.In Canada 2015 a study was conducted to measure radiation awareness among radiology technicians, residents and staff, and the study found that; only $48 \%$ of the 
participants correctly answered half of the 17 questions they were given, $23 \%$ of participates knew the correct radiation dose of chest X-ray while $50-70 \%$ underestimated it, also $50-70 \%$ underestimated the fact that exposure to radiation increases the risk of cancer ${ }^{(11)}$. A Pakistani study was conducted to assess radiology technicians' knowledge regarding radiation dose limit and radiation protections; the technicians' knowledge of radiation protections ranged from $35-95 \%$ and median score of $75 \%{ }^{12}$.

None of the previous studies were conducted in in Ain-Shams University hospitals. And there are no available data on the radiation safety knowledge among radiology technicians working in AinShams University hospitals. Thus this current study aimed at measuring the technicians' knowledge regarding radiation induced health hazards and radiation safety measures

\section{Methods:}

Study design: A Cross Sectional Study.

Study settings, population and sample:The current study was conducted in Ain-Shams University Hospitals; ElDemerdash Hospitals and Ain-Shams Specialized Hospital. All current radiology technicians exposed to ionizing radiation with at least 6 months of radiation experiencewere eligible for the study and were included, sixty one out of seventy radiology technicians agreed to participate in the study with response rate of $87 \%$.

The study included 61 radiology technicians with a respond rate. 45 of the participated radiology technicians worked in El-Demerdash Hospitals in both the Radiodiagnosis\& Intervention Radiology Department and in the Oncology Department, 15 of the participated radiology technicians worked in Ain-Shams Specialized Hospital in the Radiodiagnosis\& Intervention Radiology Department.
Sample Size:A sample size of 45 radiology technicians would produce a two sided $95 \%$ confidence interval with a width equal to 0.3 when the sample proportion is 0.4 as based on Ahmed et al, $2015^{(\mathbf{1 3})}$ study as $41.30 \%$ of the participants were considered as having poor radiation protection knowledge.

Study tool:An interview constructed questionnaire was used to assess knowledge of radiology technicians exposed to ionizing radiation regarding radiation health hazards and radiation safety measures. The questionnaire was revised by an expert professor in Radiodiagnosis and intervention radiology department and an expert professor in Occupational Medicine. A pilot study was conducted to test the questionnaire accuracy and no changes were adapted to the questionnaire. The questionnaire included sections for sociodemographic data, occupational history and knowledgeregarding radiation induced health hazards and radiation safety.

Data Management and Analysis:Radiation Knowledge Scoredepended upon 20 question; technicians were scored one mark for every "correct answer", and were scored zero for every incorrect or "I don't know" answer. The Radiation Knowledge Score included two sections: (I)knowledge of radiation induced health hazards including;fetal malformations, cancer, infertility, pregnancy complications and premature senility, and knowledge that radiation affectsbone marrow, eye, skin,GIT, respiratory system, bones, cardiovascular system andurinary system(13 questions). (II)Knowledge of Radiation safety measures includes; occupational radiation exposure dose limit per year, occupational radiation dose limit per year for pregnant workers, youngest age allowed to work in radiology,Knowledge of Egyptian Labour Law regarding occupational radiation exposure,imaging 
machine emits greatest dose of ionizing radiation, how to wear a dosimeter properlyand Knowledge that leaded Personal Protective Equipments lose their effectiveness by time ( 7 questions). The collected data was revised, coded, tabulated, presented and analyzed using Statistical package for Social Science (SPSS 20 for windows). Student $\mathrm{t}$ Testwas used to assess the statistical significance of the difference between two study group means. Chi-Square test was used to examine the relationship between two qualitative variables. Pearson correlation was used to measure the strengths of association between two quantitative variables.

Ethical consideration: Informed consents were obtained from the technicians and administrative approval fromradiodiagnosis\& interventional radiology department and oncology departmentwere obtained.

\section{Results:}

Results of the study shows that mean age of technicians was $34.8 \pm 10.54,45$ $(73.8 \%)$ of the technicians had a diploma degree,48 $(78.7 \%)$ out of the 61 technicians stated that they received preemployment orientation on radiation. Only $4(6.6 \%)$ of the 61 technicians have attended radiation safety courses (table $1)$.

As regard technicians' knowledge of radiation induced health hazards technicians' awareness of radiation health hazards, highest percentage of the technicians knew that radiation exposure causes fetal malformations 56 (91.8\%). However least percentage of the technicians $14 \quad(22.9 \%)$ knew that exposure to radiation affects renal system.As regard technicians' knowledge of radiation safety measures highest percentage of technicians knew that lead in the radiation protective equipment may loses its effectiveness after time. While least percentage of the technicians $4(6.6 \%)$ knew the occupational radiation dose limits per year (table 2). Radiology technicians' knowledge score regarding radiation safety measures and radiation health hazards mean \pm SD was $10.53 \pm$ 3.8 and out of 61 technicians $23(37.7 \%)$ scored less than $50 \%$ in the radiation knowledge score (table 3)

As regard the factors affecting technicians' radiation knowledge, male technicians scored higher $(11.2 \pm 3.9)$ in radiation knowledge score than female technicians $(9.3 \pm 3.3)$ however the difference was statistically nonsignificant $(\mathrm{P}=0.051)$. There was no statistically significant difference in the knowledge score as regards technicians' educational level, attending radiation safety courses and place of work (the hospital where the technicians worked). There was no correlation between technicians' age or duration of experience (in years) and Radiation Knowledge Score (table 4).

\section{Discussion:}

In this study it was found that only 4 $(6.6 \%)$ of the 61 technicians have attended radiation safety courses by the department reflecting defect in the radiation safety courses available for the technicians. The percentage of technicians who attended radiation safety courses were similar to a study conducted in Suez Canal university hospital in 2015 as $(88.8 \%)$ of the physicians didn't attend any radiation safety courses ${ }^{14}$ and similar to Paolicchi et al study, 2016 as they found that only $12.1 \%$ of the participants attended radiation protection courses on a regular basis; while $56.4 \%$ and $31.5 \%$ of them rarely attended or had never attended any radiation safety courses ${ }^{15}$. However these results contradict a study conducted in Uganda in 2006 as radiation safety courses were available for radiology technicians; $86.4 \%$ of the participated technicians attended radiation safety courses $^{16}$. 
In the current study, technicians' Radiation knowledge was assessed in two major domains; knowledge of radiation induced health hazards and knowledge of radiation safety measures. A total radiation knowledge score for the radiology technicians was measured and it was found that $23(37.7 \%)$ of the 61 participated technicians scored less than $50 \%$ in the radiation knowledge score. The radiation knowledge score mean was $10.53 \pm 3.8$. The radiation knowledge defect found in this current study probably reflects that radiology technicians only received basic radiology information in their academic study and that the radiation safety knowledge defect was probably a result of the inadequacy of radiation safety courses provided to the radiology technicians.Several studies were conducted to assess radiation knowledge of healthcare workers. Similar results were found in a study assessing radiation protection knowledge among physicians in Suez Canal university hospital; theknowledge scoremean was $56.5 \pm$ 15.2and the participated physicians knowledge scores ranged from $40 \%$ $60 \%$. $^{(14)}$. A study conducted in Saudi Arabia in 2015 regards radiation protection knowledge found that $41.30 \%$ of the participants had poor radiation protection knowledge as they gave less than three correct answers out of five questions ${ }^{13}$. In Indonesia a study to assess radiology technicians' knowledge regards radiation protection found that $69.3 \%$ of the technicians answered less than $50 \%$ of the questions correctly $^{(\mathbf{1 0})}$. Howevertechnicians' radiation awareness was higher in a Pakistan study asthe technicians' radiation knowledge score median score was $75 \%$ with a range of $35-95 \% \%^{12}$.

The current study found thatonly 4 $(6.6 \%)$ out of 61 technicians correctly knew the occupational radiation exposure dose limits, increase technicians' awareness of radiation safety measures is needed. Similar results was found by a study conducted in Pakistan in 2007 which found that none out of the participated technicians correctly knew the occupational permissible dose of radiation $^{12}$. However that contradicted what was found by Mojiri and Moghimbeigistudy conducted in 2011 as they found that majority of the technicians $(81.7 \%)$ correctly knew the occupational maximum permissible $\operatorname{dos}^{17}$. Contradicting Ahmed etal study conducted in Saudi Arabiain 2015; they found that $74.7 \%$ of the technicians knew maximum permissible dose limit. ${ }^{13}$

The current study found that although MRI machine does not emit ionizing radiation, $6.6 \%$ of the 61 technicians chose MRI machinesas the most hazardous investigating machine emitting the highest dose of ionizing radiation. Which reflect that there was a defect in even basic radiology knowledge among the technicians. These findings were similar to a study conducted byPaolicchi et al in 2016 as it was found that $4 \%$ of the participated technicians claimed that pelvis magnetic resonance imaging emits radiation ${ }^{15}$. Similarly a study conducted on health-care workers exposed to radiation found that $10.9 \%$ of participants stated that MRI emits larger dose of radiation than a chest $\mathrm{X}$-ray. ${ }^{18}$

The current study found that technicians knowledge of certain radiation induced health hazards was specifically higher than others; nearly all of the technicians $91.8 \%$ knew that exposure to radiation can induced fetal malformations, 90.2\% of the technicians knew that radiation can affect bone marrow, $83.6 \%$ of the technicians were aware that exposure to radiation can cause cancer, $78.7 \%$ knew that exposure to radiation can cause infertility, $67.2 \%$ knew that exposure to radiation can cause premature aging and senility and $70.5 \%$ of the technicians knew that exposure to radiation can affect the skin. However less than 50\% of the technicians were aware that 
radiation exposure can cause Bones, respiratory system, cardiovascular system and renal System affection. Probably technicians were aware the most of the common health hazards induced by radiation exposure; it is recommended to emphasis on all possible radiation induced health hazards through the academic medical education for the radiology technicians.

Similar results were found by Yurt et al study conducted in 2014 as it was found that technicians were familiar with nearly the same radiation induced health hazards; the majority of the participants 93.5\% were aware that radiation can cause cancer, $79.3 \%$ of the participants were aware that radiation exposure can cause Infertility, $76.1 \%$ were aware that radiation exposure causes Genetic disorders, $67.4 \%$ were aware that radiation exposure causes premature senility and $59.8 \%$ were aware that radiation exposure causes skin disorders ${ }^{18}$. Contradicting Ramanathan\& Ryan study, 2015; they found that 50$70 \%$ out of the participants underestimated the fact that exposure to radiation increase the risk of cancer ${ }^{11}$ and contradicting the radiologists' awareness of radiation induced health hazards found in Lynskey et al study which was conducted in 2013 as the participated radiologist stated that the organ at highest risk to be affected by radiation is the eye, then the thyroid gland and then bone marrow. ${ }^{19}$

As regard factors affecting technicians' radiation knowledge. This current study found that there was no association between radiation knowledge score and technicians' educational level.

These findings contradicted shah et al study, as they found that the radiation safety awareness is affected by the technicians' educational background; radiation knowledge score was higher for technologists with science backgrounds (bachelor BSc degree) than technicians only with high school degree with medical certificate) $)^{12}$

The current study found that there was no association between knowledge score and duration of experience in years, probably because older technicians have longer duration of experience and years of practice and consequently good radiation knowledge and equally younger technicians probably still remember more readily the radiation safety knowledge they received in their academic education; and that is probably why there was no difference in the radiation knowledge score between younger and older technicians.

These findings contradicted Shah et al study which was conducted in Pakistan in 2007 as they found that the group of technician who scored $88 \%$ in the knowledge score "highest score" were the technicians with (11-15) years of experience. ${ }^{12}$

The current study found that the knowledge score of the 4 technicians who attended the radiation safety course was nearly the same as the remaining technician who did not attend any radiation safety courses.Reflecting that not only there was inadequacy in radiation safety courses among technicians and that the radiation safety courses were sporadic rather that regularly organized but also that the way of teaching andthe content of the available radiation safety course must be revised.

\section{Conclusion}

This study found that 23 (37.7\%) scored less than $50 \%$ in the radiation knowledge score. Only $4(6.6 \%)$ of the technicians attended radiation safety courses. No association was found between technicians' gender, age, educational level, the hospital where the technicians worked nor attending radiation safety courses and radiation knowledge score.

Recommendation:Provided educational courses regarding workplace hazards and 
increase availability of radiation safetytraining courses and revise the content and teaching techniques of the already available courses is recommended.

\section{References:}

1. US EPA United States Environmental Protection Agency, radiation protection, radiation basics, last updated on September 21, 2015, http://www.epa.gov/radiation/understand /radiation_radioactivity.html

2. US NRC United States nuclear regulatory commission, Page Last Reviewed/Updated Friday, October 17, 2014;http://www.nrc.gov/aboutnrc/radiation/around-us/usesradiation.html

3. Holmberg O., Czarwinski R. and Mettler F., The importance and unique aspects of radiation protection in medicine, European Journal of Radiology, 2010; 76: 6-10

4. Frieben A. Demonstration eines cancroids des rechtenhandruckens, das sichnachlangdauerndereinwirkung von roentgenstrahlenentwickelthatte.

FortschrRoentgenstr 1902; 6:106-111. Cited in: Yoshinaga S. Mabuchi K., Sigurdson A. J. , Doody M. M. and Ron E., Cancer Risks among Radiologists and Radiologic Technologists: Review of Epidemiologic Studies, Radiology (Radiological Society of North America RSNA), 2004; 233 (2): 313-321

5. Henshaw P. S. and Hawkins J. W., Incidence of leukemia in physicians. J Natl Cancer Inst 1944; 4:339-346. Cited in: Yoshinaga S. Mabuchi K., Sigurdson A. J. , Doody M. M. and Ron E., Cancer Risks among Radiologists and Radiologic Technologists: Review of Epidemiologic Studies, Radiology (Radiological Society of North America RSNA), 2004; 233 (2): 313-321

6. Ulrich H., Incidence of leukemia in radiologists. N Engl. J Med 1946; 234:45-46. cited in: Yoshinaga S. Mabuchi K., Sigurdson A. J., Doody M.
M. and Ron E., Cancer Risks among Radiologists and Radiologic Technologists: Review of Epidemiologic Studies, Radiology (Radiological Society of North America RSNA), 2004; 233 (2): 313-321

7. Lewis E. B., Leukemia and ionizing radiation. Science 1957; 125:965-972. cited in: Yoshinaga S. Mabuchi K., Sigurdson A. J. , Doody M. M. and Ron E., Cancer Risks among Radiologists and Radiologic Technologists: Review of Epidemiologic Studies, Radiology (Radiological Society of North America RSNA), 2004; 233 (2): 313-321

8. Court Brown W. M. and Doll R., Expectation of life and mortality from cancer among British radiologists. British Medical Journal, 1958; 34:181-187.

9. Kiah J. and Stueve D., The Importance of Radiation Safety for Healthcare Workers as Well as patients, Cath lab digest, 2012; 20 (1)

10. Abu Arrah A. R. M., Faisal A. and Sadewa A. H., Assessment of the application level of Radiation protection and awareness of Radiation safety regulations among the Radiographers at Yogyakarta Special Region, Indonesia, Journal of Medical Sciences, 2001; 43 (2): 116-125

11. Ramanathan S. and Ryan J., Radiation awareness among radiology residents, technologists, fellows and staff: where do we stand? Insights imaging journal, 2015; 6 (1): 133-139.

12. Shah A. S., Begum N., Nasreen S. and Khan A., Assessment of radiation protection awareness levels in medical radiation science technologists -a pilot survey, Journal of Postgraduate Medical Institute JPMI, 2007; 21(03): 169-172 13. Ahmed R. M., Elamin A. M. T., Elsamani M. and Hassan W. B., Knowledge and Performance of Radiographers towards Radiation Protection, Taif, Saudi Arabia, Journal of Dental and Medical Sciences, 2015; 14 (3): 63-68 
14. Abdellah F. R., Attia A. S., Fouad A. M., Abdel-Halim A. W., Assessment of Physicians' Knowledge, Attitude and Practices of Radiation Safety at Suez Canal University Hospital, Egypt, Open Journal of Radiology, 2015; 5: 250-258

15. Paolicchi F., Miniati F., Bastiani L., Faggioni L., Ciaramella A., Creonti I., Sottocornola C., Dionisi C. and Caramella D., Assessment of radiation protection awareness and knowledge about radiological examination doses among Italian radiographers, Insights Imaging, 2016; 7: 233-242

16. Kiguli-Malwadde

E., DdunguMatovu P., Kawooya M. G., and Byanyima R. K., Radiation Safety Awareness among Radiation Workers and Clientele At Mulago Hospital, Kampala, Uganda. East and Central
African Journal of Surgery, 2006; 11 (1): 49-51

17. Mojiri, M., and Moghimbeigi A., Awareness and attitude of radiographers towards radiation protection, Journal of Paramedical Sciences (JPS), 2011; 2 (4) 18. Yurt A., Çavuşoğlu B. and Günay T., Evaluation of Awareness on Radiation Protection and Knowledge About Radiological Examinations in Healthcare Professionals Who Use Ionized Radiation at Work, Molecular Imaging and Radionuclide Therapy, 2014; 23(2): 48-53

19. Lynskey G. E., Powell D. K., Dixon R. G. and Silberzweig J. E., Radiation Protection in Interventional Radiology: Survey Results of Attitudes and Use, Journal of Vascular Intervention Radiology, 2013; 24:1547-1551 
Table (1): Technicians'sociodemographic and occupational history:

\begin{tabular}{|c|c|c|}
\hline Sociodemographic and workplace characteristics & $\mathbf{N}$ & $\%$ \\
\hline $\begin{array}{l}\text { Gender: } \\
\text { - Male } \\
\text { - } \text { Female }\end{array}$ & $\begin{array}{l}40 \\
21\end{array}$ & $\begin{array}{l}65.6 \\
34.4\end{array}$ \\
\hline $\begin{aligned} & \text { Education Level: } \\
& \text { - } \text { Diploma } \\
& \text { - } \text { University } \\
&\end{aligned}$ & $\begin{array}{l}45 \\
16 \\
\end{array}$ & $\begin{array}{l}73.8 \\
26.2 \\
\end{array}$ \\
\hline $\begin{array}{l}\text { Workplace : } \\
\text { - El-Demerdash Hospital: } \\
\text { - Ain- Shams specialized Hospital } \\
\text { Total }\end{array}$ & $\begin{array}{l}46 \\
15 \\
61 \\
\end{array}$ & $\begin{array}{r}75.4 \\
24.6 \\
100.0 \\
\end{array}$ \\
\hline Age in years $($ Mean $\pm S D)$ & \multicolumn{2}{|c|}{$34.8 \pm 10.8$} \\
\hline $\begin{array}{ll}\text { Radiology Occupational History:(Mean } \pm \text { SD) } \\
\text { - } \quad \text { Duration of Radiology Experience in Years }(\mathrm{N}=61) \\
\text { - } \quad \text { Current Job Working Hours Per Week }(\mathrm{N}=61) \\
\text { - } \quad \text { Additional Job Working Hours Per Week }(\mathrm{N}=26)^{*} \\
\text { - } \quad \text { Total Hours of Exposure to Radiation Per Week }(\mathrm{N}=26)^{*} \\
\end{array}$ & \multicolumn{2}{|c|}{$\begin{array}{c}13.13 \pm 10.54 \\
36.75 \pm 9.96 \\
27 \pm 14.21 \\
64.8 \pm 17.94\end{array}$} \\
\hline 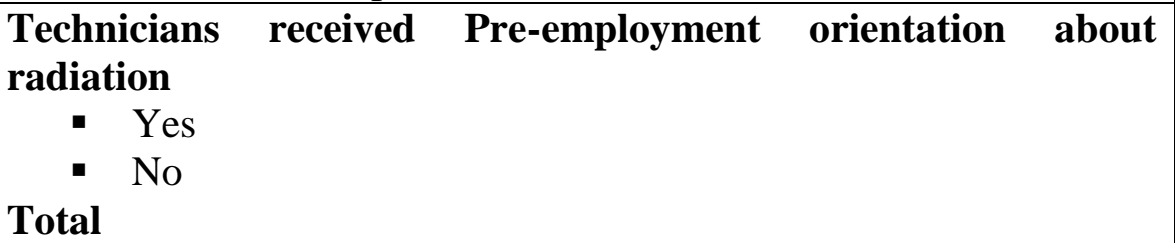 & $\begin{array}{l}\mathrm{N} \\
48 \\
13 \\
61\end{array}$ & $\begin{array}{r}\% \\
78.7 \\
21.3 \\
100.0\end{array}$ \\
\hline $\begin{array}{l}\text { Technicians attended radiation safety courses after admitting to } \\
\text { the job } \\
\text { - Yes } \\
\text { - No } \\
\text { Total }\end{array}$ & $\begin{array}{r}\mathrm{N} \\
4 \\
57 \\
61\end{array}$ & $\begin{array}{r}\% \\
6.6 \\
93.4 \\
100.0 \\
\end{array}$ \\
\hline
\end{tabular}

*Only 26 of the technicians were exposed to ionizing radiation in their additional work. 
Table (2): Technicians' Knowledge regards Radiation Health Hazards \& Radiation Safety Measures:

\begin{tabular}{|c|c|c|}
\hline Technicians' knowledge Items & $\mathbf{N}$ & $\%$ \\
\hline $\begin{array}{l}\text { Technicians' knowledge that Radiation exposure causes } \\
\text { the following health effects: } \\
\text { - Fetal Malformations } \\
\text { - } \text { Bone Marrow effects } \\
\text { - } \text { Cancers } \\
\text { - } \text { Fertility } \\
\text { - } \text { complications to Pregnant women } \\
\text { - Skin effects } \\
\text { - Premature Aging \& Senility } \\
\text { - Gastrointestinal tracteffects } \\
\text { - } \text { Respiratory Systemeffects } \\
\text { - } \text { Canes effects } \\
\text { - } \text { Renal Systemeffects }\end{array}$ & $\begin{array}{l}56 \\
55 \\
51 \\
48 \\
45 \\
44 \\
43 \\
41 \\
31 \\
30 \\
24 \\
24 \\
14\end{array}$ & $\begin{array}{l}91.80 \\
90.20 \\
83.60 \\
78.70 \\
73.80 \\
72.10 \\
70.50 \\
67.20 \\
50.80 \\
49.20 \\
39.30 \\
39.30 \\
22.90\end{array}$ \\
\hline $\begin{array}{l}\text { Technicians' knowledge of Radiation Safety Measures: } \\
\text { - Knowledge of Occupational Radiation Exposure } \\
\text { Dose limit. } \\
\text { - Knowledge of Egyptian Labour Law. } \\
\text { - The youngest age allowed to work in radiation } \\
\text { field. } \\
\text { - Knowledge of Occupational Radiation Exposure } \\
\text { Dose limit for pregnant workers. } \\
\text { - How to use a Dosimeter properly. } \\
\text { - Knowledge that Lead in the radiation protective } \\
\text { equipments may Loses its effectiveness after } \\
\text { time }\end{array}$ & $\begin{array}{r}5 \\
8 \\
\\
11 \\
\\
33 \\
44\end{array}$ & $\begin{array}{r}6.6 \\
8.2 \\
13.1 \\
18.0\end{array}$ \\
\hline $\begin{array}{l}\text { Technicians' knowledge of which Radiological Machine } \\
\text { Emits Highest Dose of Ionizing Radiation: } \\
\text { - Correct answer: CT scan } \\
\text { - Incorrect answer: } \\
\bullet \quad \text { X- rays } \\
\text { • MRI } \\
\text { - Ultrasound } \\
\text { - "I Don't Know" answer } \\
\text { Total }\end{array}$ & $\begin{array}{r}18 \\
4 \\
0 \\
8 \\
61\end{array}$ & $\begin{array}{r}50.8 \\
29.5 \\
6.6 \\
0.0 \\
13.1 \\
100.0\end{array}$ \\
\hline
\end{tabular}


Table (3): Radiation Knowledge Score:

\begin{tabular}{|l|r|}
\hline Radiation Knowledge Score & Descriptive \\
\hline Radiation Knowledge Score "20 Questions": & $10.53 \pm 3.8$ \\
" Mean \pm SD & $0-17$ \\
\hline Distribution of technicians according to their & $\mathbf{N}(\%)$ \\
Radiation knowledge score: & $23(37.7)$ \\
- scored less than 50\% & $38(62.3)$ \\
Total scored 50\% or more & $61(100.0)$ \\
\hline
\end{tabular}

Table (4): Factors Affecting Radiation Knowledge Score:

\begin{tabular}{|c|c|c|c|}
\hline $\begin{array}{c}\text { Factors Affecting Radiation Knowledge } \\
\text { Score }\end{array}$ & $\begin{array}{c}\text { Knowledge } \\
\text { score Mean } \pm \\
\text { SD }\end{array}$ & $\begin{array}{c}\text { Test of } \\
\text { statistical } \\
\text { significant }\end{array}$ & $P$ value \\
\hline $\begin{array}{l}\text { Gender: } \\
\text { - } \quad \text { Male }(\mathrm{N}=40) \\
\text { - } \quad \text { Female }(\mathrm{N}=21)\end{array}$ & $\begin{array}{l}11.2 \pm 3.9 \\
9.3 \pm 3.3\end{array}$ & $\mathrm{t}=2.000$ & $\mathrm{P}=.051$ \\
\hline $\begin{array}{l}\text { Education Level } \\
\text { - } \quad \text { Diploma }(\mathrm{N}=45) \\
\text { - } \quad \text { University }(\mathrm{N}=16)\end{array}$ & $\begin{array}{l}10.5 \pm 3.9 \\
10.6 \pm 3.6\end{array}$ & $\mathrm{t}=0.122$ & $\mathrm{P}=0.903$ \\
\hline $\begin{array}{l}\text { Workplace } \\
\text { - El-Demerdash Hospital }(N=46) \\
\text { - } \quad \text { Ain-Shams Specialized Hospital }(\mathrm{N}=15) \\
\end{array}$ & $\begin{array}{l}10.3 \pm 3.9 \\
11.3 \pm 3.2\end{array}$ & $\mathrm{t}=0.949$ & $\mathrm{P}=0.346$ \\
\hline $\begin{array}{l}\text { Attending Radiation Safety Courses } \\
\text { - } \quad \text { Yes }(\mathrm{N}=4) \\
\text { - No }(\mathrm{N}=57)\end{array}$ & $\begin{array}{l}10.5 \pm 1.3 \\
10.5 \pm 3.9\end{array}$ & $\mathrm{t}=0.013$ & $\mathrm{P}=0.989$ \\
\hline \multicolumn{2}{|l|}{ Technicians' Age in years $(N=61)$} & $(\mathrm{r})=0.015$ & $\mathrm{P}=0.907$ \\
\hline \multicolumn{2}{|l|}{ Duration of radiology Experience in years $(N=61)$} & $(\mathrm{r})=0.080$ & $\mathrm{P}=0.540$ \\
\hline
\end{tabular}

